\title{
Profiling and Geo-Tagging of Rubber Tree Plantation through Geographic Information System
}

\author{
Eduardson E. Talosig, Cerenio Adriatico, Fil Ryan P. Yap \\ College of Business and Management, Southern Leyte State University, San Juan, Philippines \\ Email: instructorslsu@gmail.com
}

How to cite this paper: Talosig, E.E., Adriatico, C. and Yap, F.R.P. (2019) Profiling and Geo-Tagging of Rubber Tree Plantation through Geographic Information System. Open Access Library Journal, 6: e5460. https://doi.org/10.4236/oalib.1105460

Received: May 10, 2019

Accepted: July 22, 2019

Published: July 25, 2019

Copyright $\odot 2019$ by author(s) and Open Access Library Inc.

This work is licensed under the Creative Commons Attribution International License (CC BY 4.0).

http://creativecommons.org/licenses/by/4.0/ (c) (i) Open Access

\begin{abstract}
The application of geographic information system technology is now widely accepted in the agriculture industry. This study demonstrated the applicability of the technology tool in managing a rubber tree demonstration farm of the Southern Leyte State University-San Juan. Using a global positioning system (GPS) instrument, each tree was measured using waypoint in identifying the unique character of the tree. The data collected and stored in the GPS were converted into attributes that were stored in a table and linked to the feature by a unique identifier. In developing a database structure, relationships were established correctly between spatial feature classes and non-spatial feature classes of the rubber tree demonstration farm. The actual results paved for the establishment and assignment of unique rubber tree identification number determined the exact quantity of trees ready for tapping and identified available land area considered potential for the expansion of the demonstration farm. Implementing the rubber tree management system using the geographic information system (GIS) can be a potent tool for managing and monitoring risk factors for all rubber trees. The data generated in this study bring some immediate benefits to the rubber tree plantation project and also demonstrate the value of integrating the GIS technology in managing other physical resources and assets owned by the university.
\end{abstract}

\section{Subject Areas}

Education, Sociology

\section{Keywords}

Unique Rubber Tree Identification Number, Tapping, Monitoring Risk Factors 


\section{Introduction}

The passage of Republic Act 10,089 creating the Philippine Rubber Research Institute signified a milestone in the full development of the rubber industry sector of the country aimed to propel various products of rubber to become critical contributors to the country's economic growth. The law likewise enabled the PRRI to implement different research endeavors that stimulated the growing interest in rubber plantation and production. In 2012, the Department of Industry reported, the rubber industry produced 442,990 metric tons of rubber contributing around $\mathrm{PhP} 3.358$ billion to the gross domestic product of the country. In other countries, rubber also provided both substantial and alternative incomes to landholders, farmers, and the communities [1] [2] [3] [4].

Southern Leyte State University and the Department of Agriculture-Bureau of Agricultural Research signed a memorandum of agreement (MOA) in 2010 for undertaking the promotion of the rubber industry planting and production in Eastern Visayas. A seed fund of PhP 3.1 million was provided to the University in the construction of the rubber research and training center, processing and storage facility, nursery greenhouse, and procurement of assorted small tools and implements. In the same year, a techno-demo farm planted with rubber trees was established with an area of 1.6 hectares. The tapping of rubber trees starts within the fifth to the seventh year after planting. It will continue for the next 25 to 30 years. Tapping uses a special knife to slit the bark to wound the resin canals without damaging the cambium [5] [6] [7] [8]. The utilization of geographic information system for spatial data analysis has been applied in forest inventory, land cultivation, terrains, rainfall, and the like [6] [8] [9] [10] [11]. The utilization of geographic information system in the academe, business, and natural resource management is useful in rendering sound economic decisions by managers and practitioners in the field [12] [13] [14] [15].

This study demonstrated the integration of Geographic Information System (GIS) with the management of the rubber tree demonstration farm [9]. There are few current studies carried out using the GIS tool. The actual results paved for the establishment of unique rubber tree identification number, determined the number of trees that are ready for tapping, and established an available area for expansion of the demonstration farm. Implementing the rubber tree management system using GIS can be a potent tool for managing and monitoring risk factors for all vertical rubber trees plantation. The data generated in this study bring some immediate benefits to the university's rubber tree plantation project and also demonstrate the value of integrating GIS technology with the rubber tree plantation management for other utilities.

The main intent and purpose of the study was to develop a geo-referenced map of the rubber tree demonstration farm of Southern Leyte State University-San Juan by profiling and assigning a permanent rubber tree identification number and determining trees that were ready for harvesting. 


\section{Materials and Methods}

\subsection{Materials}

The equipment and software utilized to accomplish are the following:

\section{Hardware}

a) Hand Held GPS (GARMIN etrex 30)

b) One unit Laptop Computer

Specification:

Processor: Intel core I3 $1.7 \mathrm{GHz}$

Memory: $4 \mathrm{~GB}$

Hard Disk: 400 GB

Operating System: Widows 764 Bit

\section{Software}

a) Quantum Geographic Information System (QGIS)

Specification:

QGIS version

2.12.0-Lyon

Compiled against $\mathrm{Qt}$

Compiled against GDAL/OGR

1.11 .3

Compiled against GEOS

3.5.0-CAPI-1.9.0

PostgreSQL Client Version

QWT Version

QScintilla2 Version

\subsection{Methods}

\section{Profiling of the Rubber Tree Farm}

Using a global positioning system GPS instrument, each tree was marked using waypoint in identifying the unique character of the tree. The complete data collected that were stored in the GPS were converted into attributes, created a table, and linked to the unique identifier. In developing a database structure, relationships must be established correctly between feature spatial classes and non-spatial feature categories of the rubber tree demonstration farm. To, identify the rubber trees ready for tapping, the height and width of every single trunk were measured. Harvestable trees are those with measurement of equal to higher than $120 \mathrm{~cm}$ in height and $50 \mathrm{~cm}$ in diameter.

\section{Designing of Identification Number for the Rubber Tree}

Designing a unique identification number of each rubber tree was a priority in the validation of the data. The parameter was utilized to project the map of whole Southern Leyte Province. The Province was divided into horizontal and vertical lines known as gridlines, measured 1000 meters for every square. Thus, 1 $\mathrm{k}$ meter block was known as the main block. Every block assigned a designated number for identification covered the whole Province. By getting the exact distance of the main block, the parameter was used in QGIS software. To isolate the different municipalities in the Province, the sub-blocking technique was developed. The sub-block was measured about $20 \times 20$ meters inside the main block. 
Every main block was composed of a sub-block representing the location of every rubber tree in each municipality in the Province. To pinpoint the location of the barangay in each municipality in the Province the Philippine Standard Geodetic Code (PSGC) has been used to support the distinctiveness of the ID.

\section{Simulating Rubber Farm Management}

To model the supervision of the rubber plantation through GIS technology map projection was drawn. The projected map was used with the coordinate's reference system of WGS-84 and a datum of UTM zone 51 to compliment the location area. In determining the rubber trees ready for tapping or not two sets of maps were developed and overlaid on the Google Earth projected elevation model to visualize the farm. Rubber trees were represented by waypoint using the reference coordinate system of WGS-84 and colored by red and green points.

\section{Results and Discussion}

Figure 1 shows the topographical map of the Province of Southern Leyte, Philippines using the coordinate reference system WGS84 with the datum of UTM 51. WGS84/UTM51 was the basis of the entire projected map applied in the study. The coordinate reference system (CRS) practically fitted in the location for developing spatial data analysis. The uniformity of the CRS assisted the investigation in displaying information about the characteristics of an area.

Figure 2 provided the basis for designing the main block measuring 1000 meters each square. The computed values are substituted for the $\mathrm{X}$ minimum and $\mathrm{X}$ maximum and $\mathrm{Y}$ minimum and $\mathrm{Y}$ maximum axis on the grid extent under the vector grid polygon. Moreover, these gridlines were used as the parameters in calculating the exact location and distance of the projected map for the whole Southern Leyte province including the town of San Juan, the site of the rubber plantation.

Figure 3 showed the map of Southern Leyte suitable for actual computation based on the computed value using a vector grid polygon with a parameter value equivalent to $\mathrm{x}=1000$ and $\mathrm{y}=1000$ meters.

Figure 4 showed a projected map that identifies the estimated location of every planted rubber tree that carries the uniqueness of the URID. The main block was subdivided into $20 \times 20$ meter which is the sub-block grid to each location.

Figure 5 showed the 752 waypoints plotted in QGIS using the handheld GPS were the rubber tree planted. The circular tracer in the map represents the waypoints in every plant with $\pm 5 \%$ level of errors coordinate reference system in its location on the farm.

Figure 6, which showed the attribute table, presented the code and circumferential size of the trunk of the rubber tree and the exact coordinates in each location. All actual data were inputted in the attribute table and run in the QGIS program to map the geographical location of each trunk, as shown in Figure 4.

Figure 7, the attribute data of QGIS showed the URID of the rubber tree ca- 
tegorized by the PSGC code, main block code, sub-block code, and the tree trunk number. All codes were inputted in the attribute table to assign a unique identification number shown in Figure 5.

Figure 8 showed the settings of assigned and tagged URID for every tree trunk in the plantation. The code represents the attribute, reference, and profile for each rubber tree in the farm for easy access. By assigning the code, the management can easily access the profile in terms of inventory.

Figure 9 displayed the simulation model of the rubber plantation in Southern Leyte State University-San Juan Campus, Southern Leyte. It illustrated the settings and placement of harvestable tree trunks ready for tapping and non-harvestable rubber tree trunks. The red star shapes represented by waypoints indicate the logs prepared

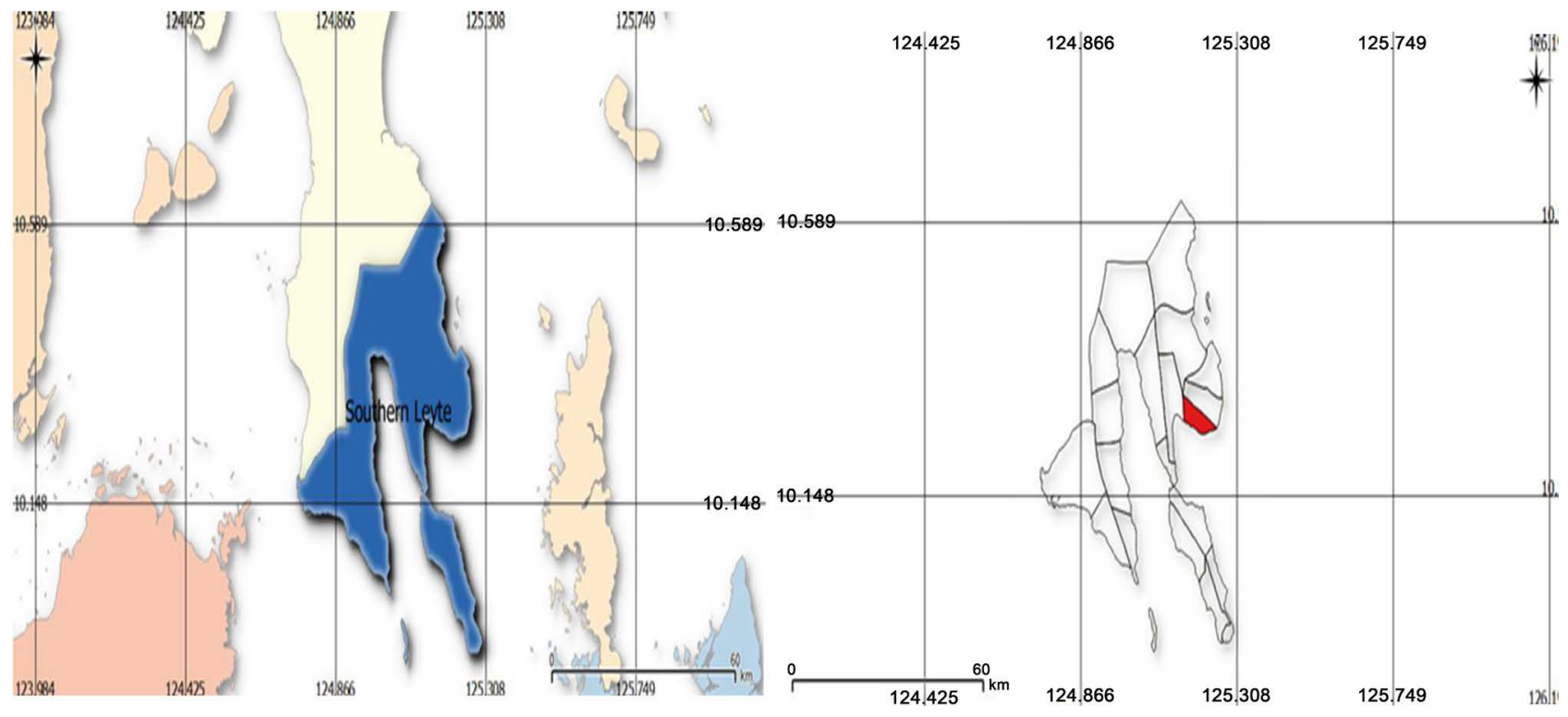

Figure 1. Topographical map of Southern Leyte (blue) and the town of San Juan (red).

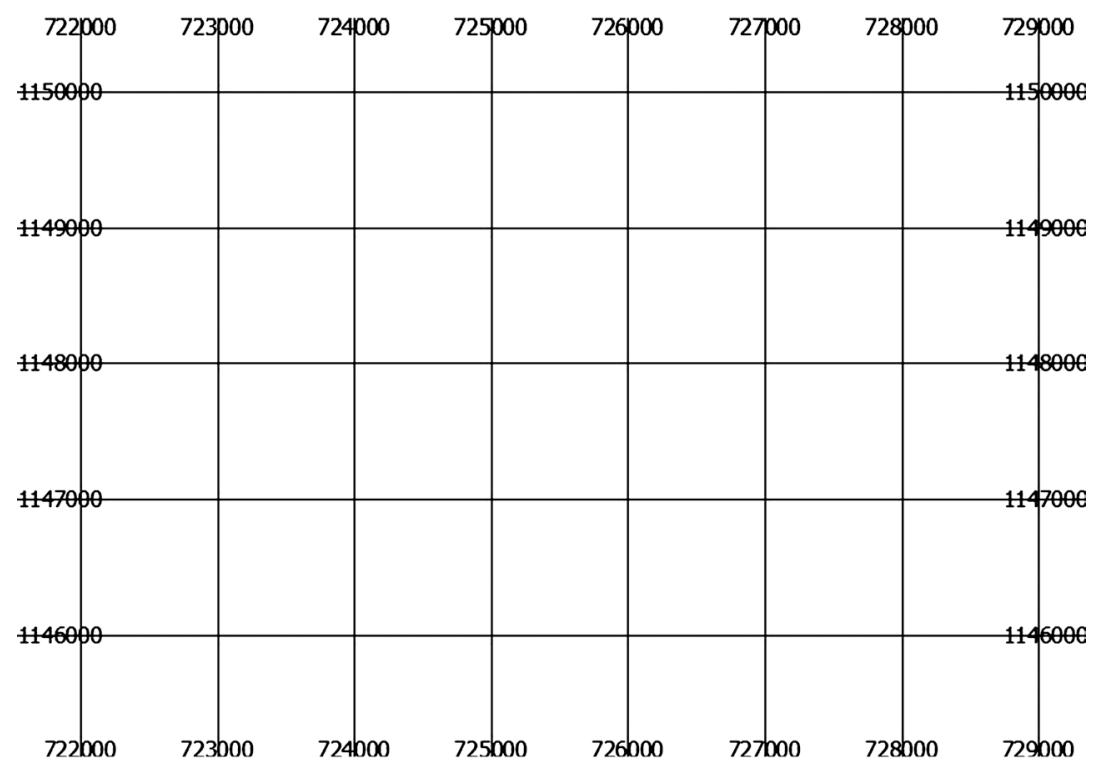

Figure 2. The 1 square kilometer gridlines. 


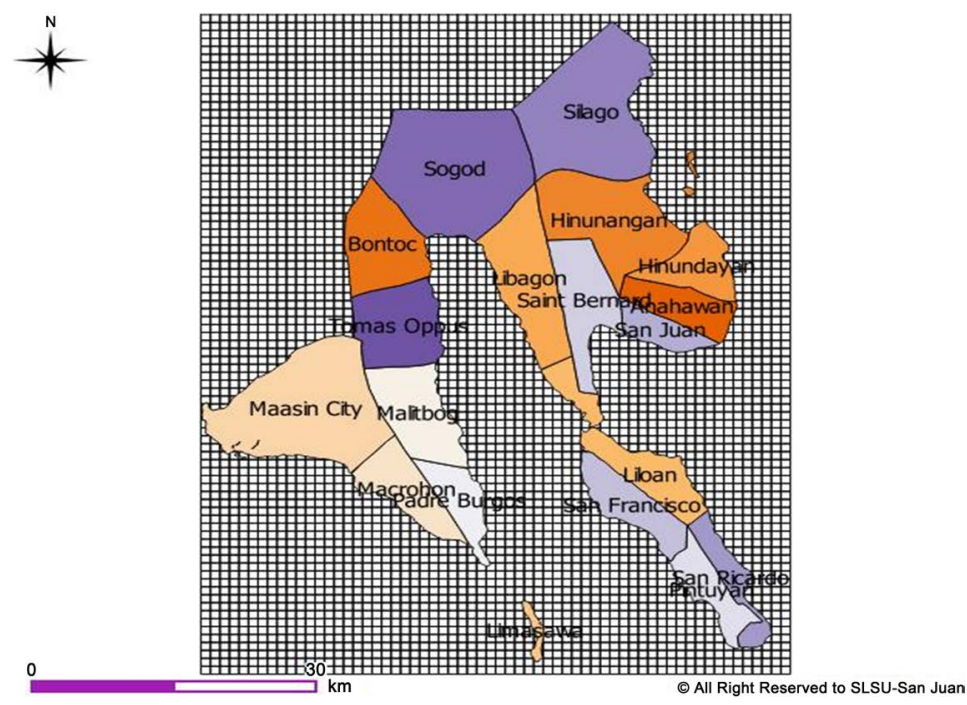

Figure 3. Projected map of Southern Leyte fitted to 1 sq.km.
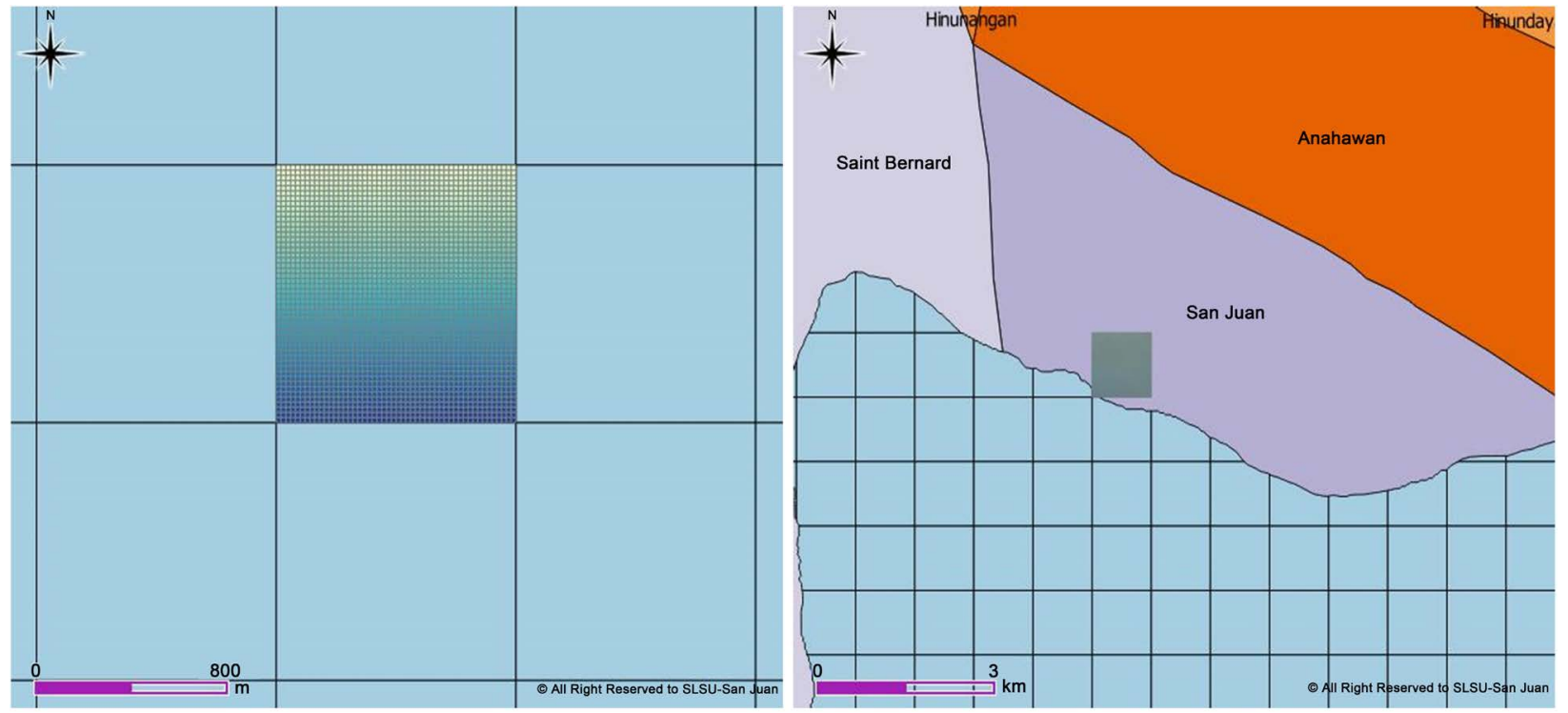

Figure 4. 20 square meter sub block.

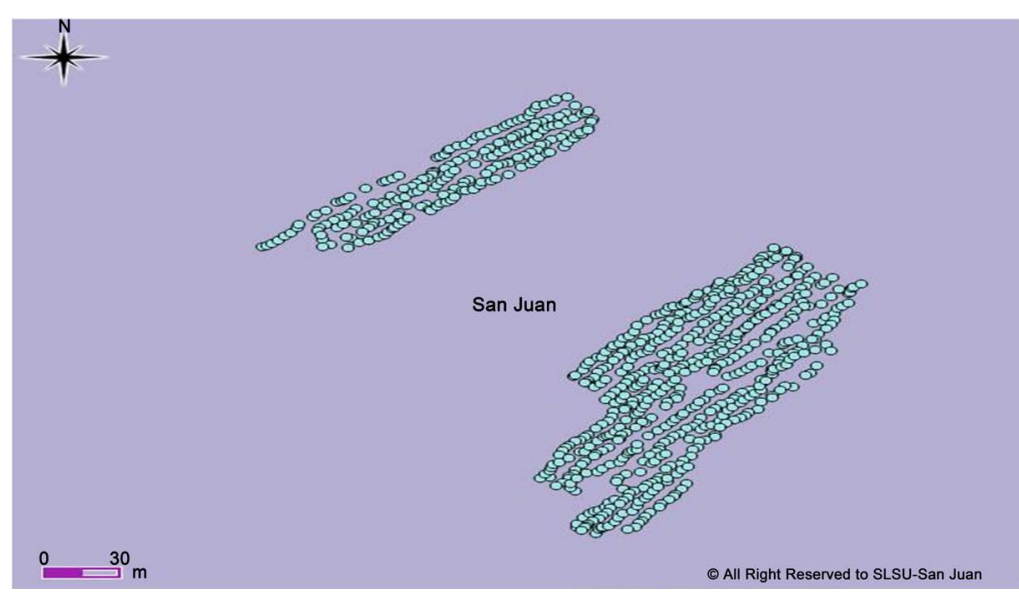

Figure 5. Projected map of the Rubber Tree Plantation using GPS waypoints. 


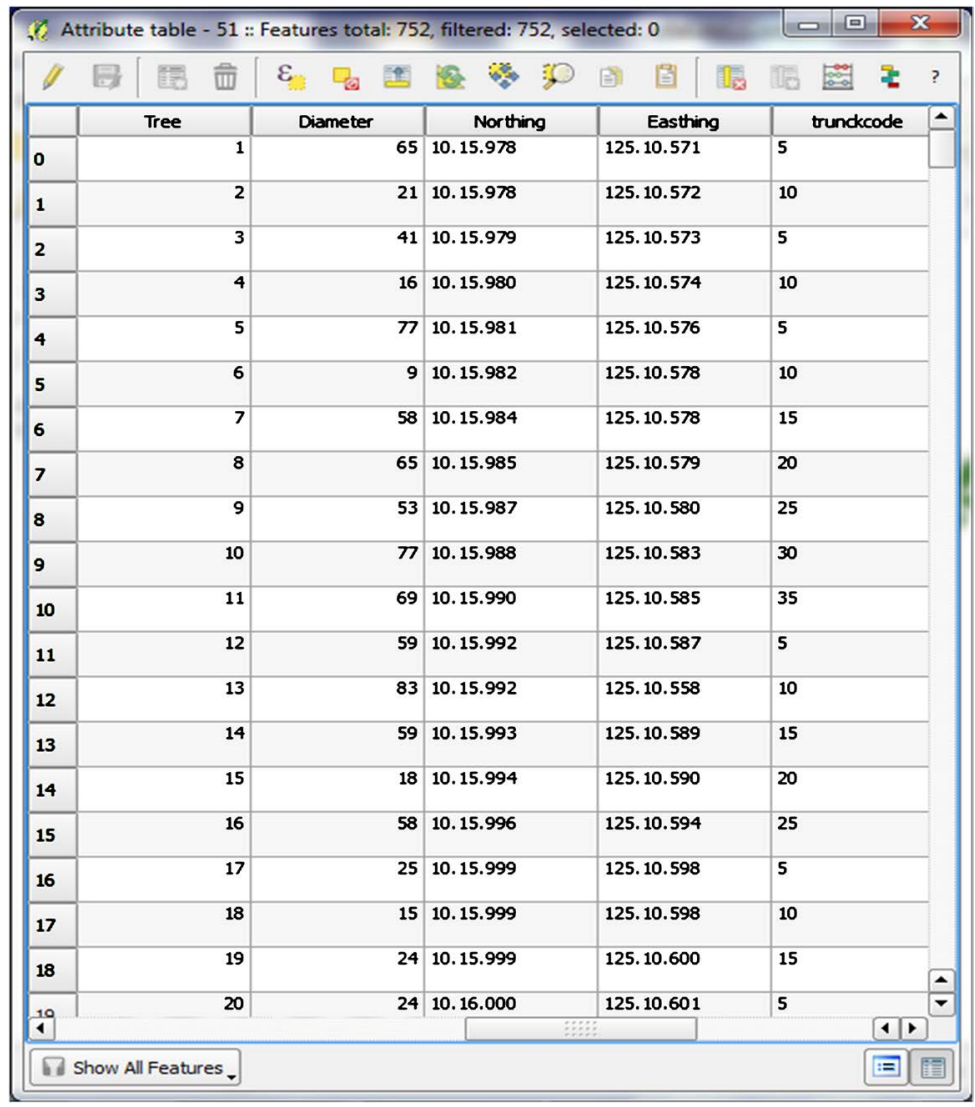

Figure 6. Database profile of the rubber tree plantation.

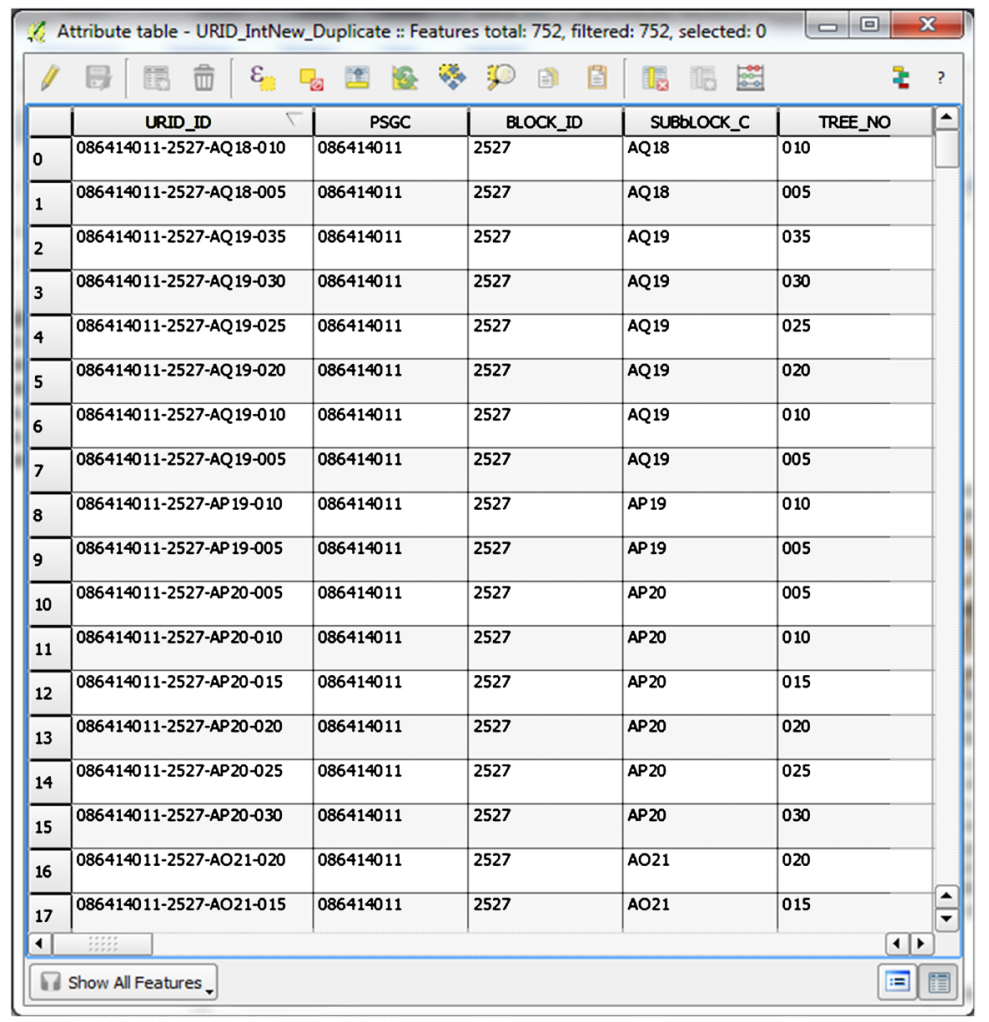

Figure 7. Database record of the URID number. 


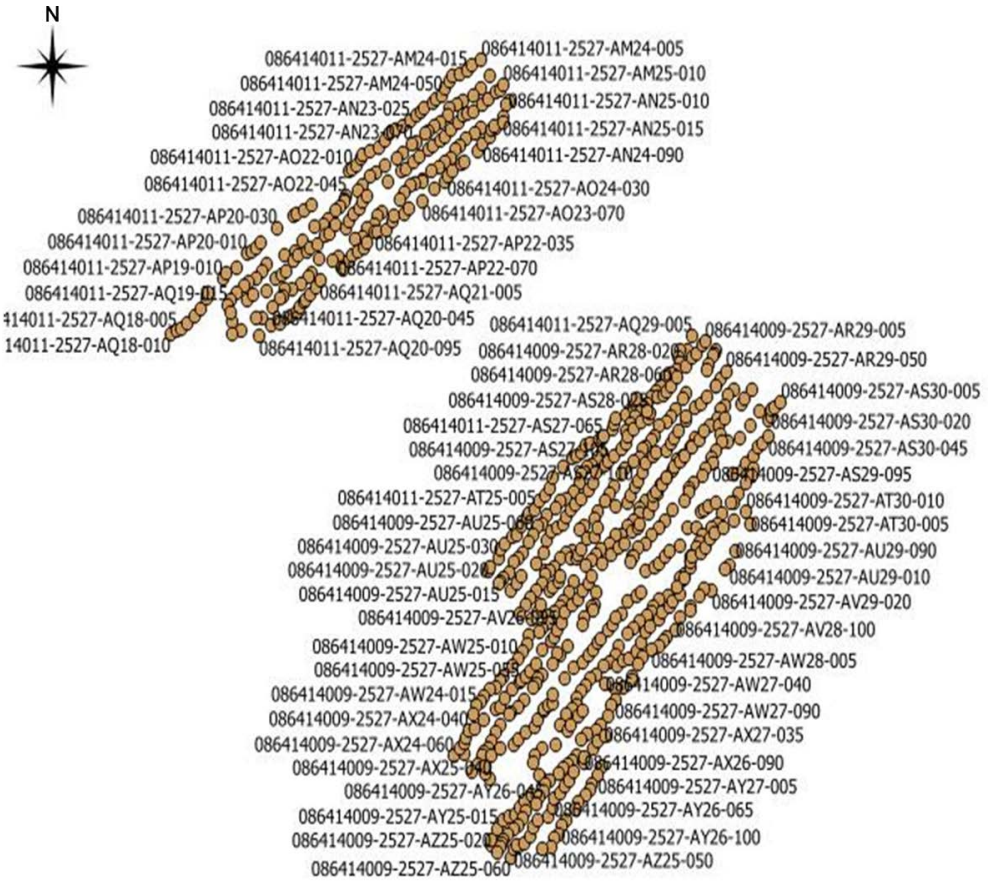

$0 \quad 30$

(c) All Right Reserved to SLTU-San Juan

Figure 8. Projected map of Rubber Tree Location with corresponding URID number.
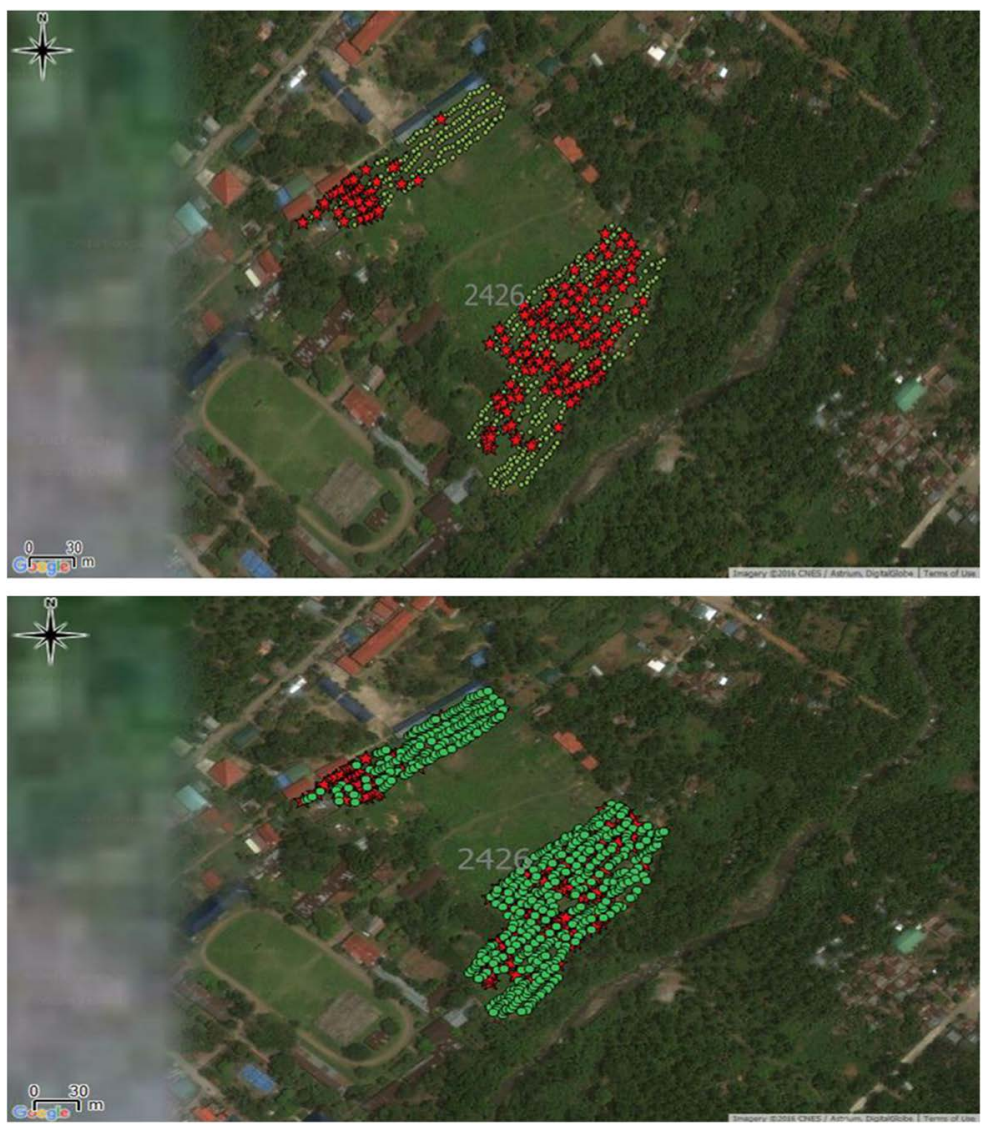

Figure 9. Digital satellite imagery of the farm overlay the harvestable and non-harvestable location rubber trees. 
for tapping. On the other hand, the green circle shapes are the rubber tree trunks that are not yet ready for tapping.

Figure 10 described the percentage number of harvestable and non-harvestable rubber trees in the plantation. The visualization of the histogram would help the management to improve and support the information needed for planning and decision making. Of the 752 rubber trees, 166 trees were determined ready for tapping. The remaining 586 trunks were projected for harvesting three months later.

\section{Soil and Climatic Requirements for Rubber Tree Farming}

In general, the growing of rubber trees usually thrives in a typical humid condition of tropical countries in Asia, South America and Africa requiring an average temperature between 25 and 280 Celsius. Cultivating the trees also requires an $80 \%$ atmospheric humidity with moderate wind speed, bright sunshine, and an average rainfall of $2000 \mathrm{~mm}$ evenly distributed throughout the year according to the Bureau of Soils and Water Management of the Department of Agriculture. Growing the species does not distinguish between dry and wet seasons. In the town of San Juan where the rubber tree demonstration farm is located, has the following soil type characteristics comprising of rough mountainous with 1590/38.83\%, San Miguel silt with 389.5/9.42\%, Taal fine sandy loam of $1530.9 / 37.38 \%$, and Guinbalon clay of $588.56 / 14.37 \%$. The town has no dry season for January-December, yet the months of June until December are the wet season. The entire province has an annual mean precipitation of $1700 \mathrm{~mm}$ and an average yearly temperature of $27^{\circ} \mathrm{C}$ [16]. The optimal $\mathrm{pH}$ or acidity level requirement for cultivating rubber farming should be in the range of soil $\mathrm{pH} 4$ 6.5 [16] [17] [18]. Similarly, most of the soils in the province have an acidic $\mathrm{pH}$ value of $<6.75$ [19] [20] [21] [22]. As rubber trees grow under different climatic conditions, the entire province is highly suitable to engage in the planting and production of rubber.

Design of the Unique Identification ID (URID)

The CRS WGS84 with the UTM equal to 51 has been utilized for the entire

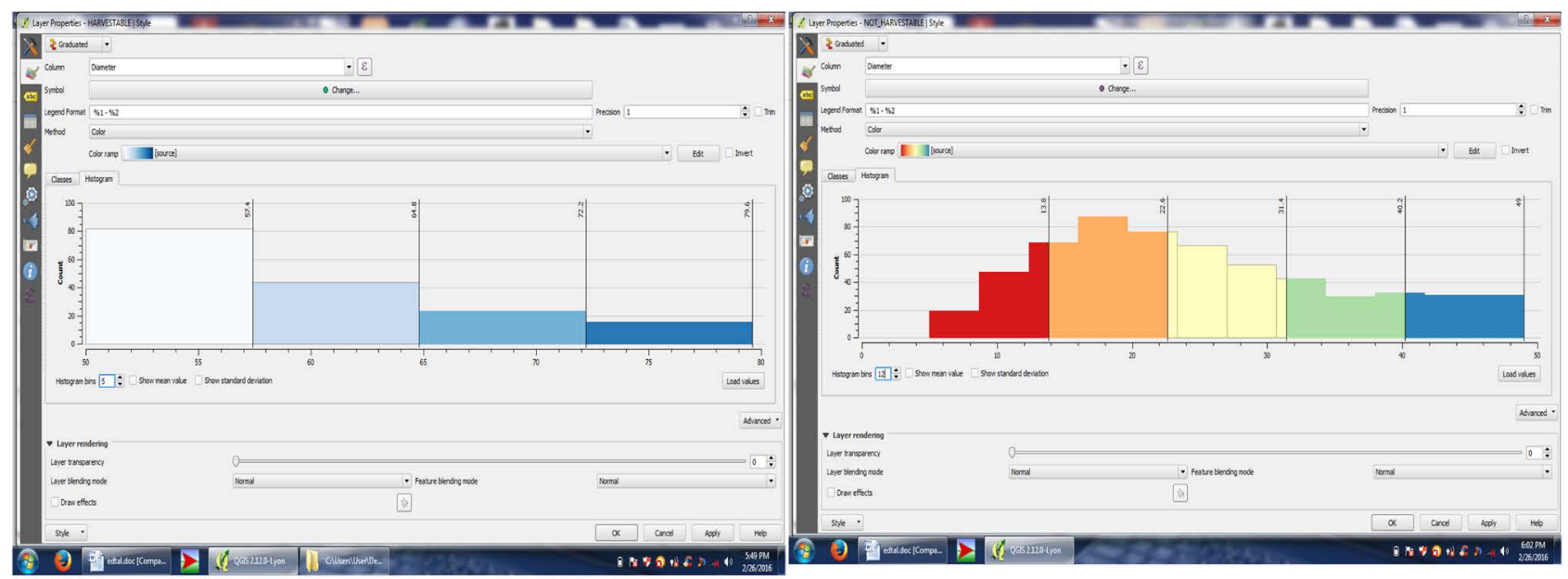

Figure 10. The histogram of harvestable \& non harvestable rubber tress. 
map projection on the study. Figure 1 discussed where we could find the Province of Southern Leyte. The town of San Juan is one of the municipalities in the province with the longitude coordinate between $10.33330 \mathrm{~N} 125.18330 \mathrm{E}$ on the location of the rubber plantation.

In designing the unique rubber identification for the trees shown in Figure 2, the researchers developed a projected map that supplements the main block cover the whole province of Southern Leyte. It was composed of 5146 square boxes measuring $1 \mathrm{~km}$ each for every square. Each plate was systematically analyzed and configured to ensure identity. To simplify the process of this study, every box was coded and formatted using three digits numbering system. The researchers also designed the sub-blocking technique to locate the possible site of every rubber tree planted in a particular area. It was measured by 20 meters for both squares. In other words, all main block was made up of sub-blocks.

These sub-blocks represent the number of rubber trees planted in the same location and also coded with the combination of letters and figures. The coded numbers and letters have been introduced for trouble-free access for each tree trunk and coded AA01 up to BX50, as shown in Figure 4.

In Figure 11 the PSGC code was used to pinpoint the different barangays in every municipality in the province. Each barangay has been coded by the PSGC code to identify the different barangays for the entire Philippines. However, for the uniqueness of the ID number, PSGC numbering system has been integrated into the URID to locate and isolate each barangay in Southern Leyte as shown in Figure 12. Therefore, the study can identify the rubber tree plantation in different municipalities and barangays in the Philippines, as shown in Figure 7.

In assigning the rubber tree trunk numbering of the plantation, the researchers analyzed and designed a coding system. Every tree was assigned a numbering system starting by 05 and incremented by 5 for each trunk, intended for what if scenario. Example supposed the rubber tree planted in a designated area died it will be numbered from 06 to 09 , as shown in Figure 7. The URID numbering and coding system can realize the profiling of rubber tree plantation, Figure 7 and Figure 8 including the CRS of a particular rubber tree trunk, the diameter of the tree and location of the harvestable and non-harvestable trunk. The coding was composed of PSGC code, main block code, sub-block code, and the trunk numbering system shown in Figure 13 below.

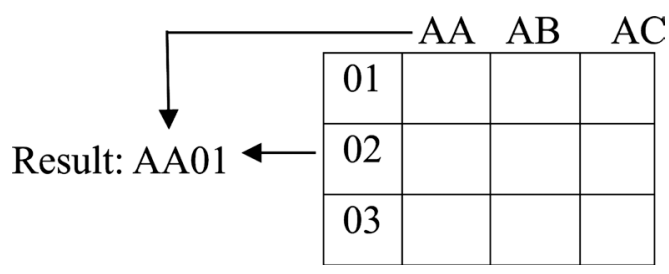

Figure 11. Illustration of the sub-blocking technique.

\section{1}

Figure 12. PSGC assigned to Barangay San Jose, San Juan, Southern Leyte. 


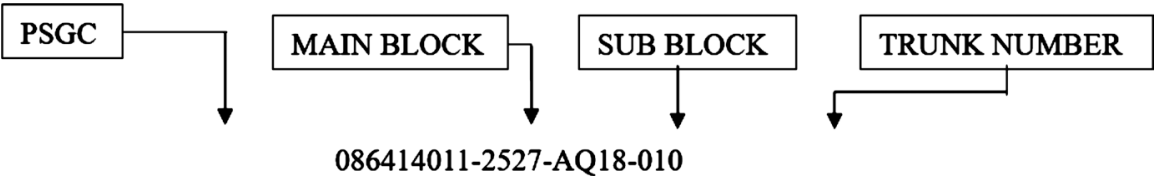

Figure 13. Model developed of the unique rubber tree ID.

Proper managing of the rubber tree plantation is an essential requirement for the sustainability of the project. The process information developed using GIS would readily assist managers in effectively monitoring the available trees ready for tapping. As presented in Figure 9, only 166 trees out of 752 were identified as capable of tapping. Given this information, the management would also be able to determine the number of rubber tree trunks that would yield higher outputs.

\section{Conclusion}

The adoption of the geographic information system (GIS) technology across all sectors of various industries can be a potent tool in collecting, storing and managing of data sources used in rendering sound and effective managerial decision-making process. The application of the GIS technology in mapping the rubber tree farm and assigning of a unique rubber tree identification number enables university officials to monitor growth and mortality rates of the trees, simulate the actual number of trees available for tapping and predict expected revenues from the sale of harvested latex. Rubber tree cultivation is suitable on soils with a $\mathrm{pH}$ of $<6.75$ and can withstand under different climatic environment. The current research mainly focused on assigning a unique rubber tree identification number (URID) for locating the trees that included the tracking, identifying, and recording of the diameter of each tree ready for harvesting. Calculating the estimated gross income and available area for future cultivation might be covered in future research. However, the model generated in this study brings immediate benefits to the rubber tree plantation project of the university and also demonstrates the value of integrating GIS technology in managing other facilities of the campus.

\section{Recommendation and Future Work}

The suggestions hereunder are offered as recommendations to improve the prevailing conditions revealed in this study.

1) The SLSU-San Juan Rubber Research Office should adopt and implement the tagging of the unique rubber identification in profiling the rubber tree demonstration farm.

2) Other campuses of Southern Leyte State University engaged in nursery production and planting of rubber should be encouraged to adopt the technology in profiling and managing the farm.

3) Neighboring communities and farmers should be provided with intensive orientation in profiling of their farms using the geographic information system technology. 
4) Conduct a parallel study to verify, compare, and enhance a more significant understanding of the importance of GIS technology adoption.

\section{Conflicts of Interest}

The authors declare no conflicts of interest regarding the publication of this paper.

\section{References}

[1] Suyanto, S., Tomich, T.P. and Otsuka, K. (2001) Land Tenure and Farm Management Efficiency: The Case of Smallholder Rubber Production in Customary Land Areas of Sumatra. Agroforestry Systems, 52, 145-160.

https://doi.org/10.1023/A:1010625019030

[2] Stern, R.M. (1965) Malayan Rubber Production, Inventory Holdings, and the Elasticity of Export Supply. Southern Economic Journal, 31, 314-323. https://doi.org/10.2307/1055761

[3] Dove, M.R. (1993) Smallholder Rubber and Swidden Agriculture in Borneo: A Sustainable Adaptation to the Ecology and Economy of the Tropical Forest. Economic Botany, 47, 136-147. https://doi.org/10.1007/BF02862016

[4] Manivong, V. and Cramb, R.A. (2008) Economics of Smallholder Rubber Expansion in Northern Laos. Agroforestry Systems, 74, 113-125. https://doi.org/10.1007/s10457-008-9136-3

[5] Rao, P.S., Saraswathyamma, C.K. and Sethuraj, M.R. (1998) Studies on the Relationship between Yield and Meteorological Parameters of Para Rubber Tree (Hevea brasiliensis). Agricultural and Forest Meteorology, 90, 235-245. https://doi.org/10.1016/S0168-1923(98)00051-3

[6] Kush, A., Goyvaerts, E., Chye, M.L. and Chua, N.H. (1990) Laticifer-Specific Gene Expression in Hevea brasiliensis (Rubber Tree). Proceedings of the National Academy of Sciences, 87, 1787-1790. https://doi.org/10.1073/pnas.87.5.1787

[7] Guo, Z., Zhang, Y., Deegen, P. and Uibrig, H. (2006) Economic Analyses of Rubber and Tea Plantations and Rubber-Tea Intercropping in Hainan, China. Agroforestry Systems, 66, 117-127. https://doi.org/10.1007/s10457-005-4676-2

[8] Fox, J. and Vogler, J.B. (2005) Land-Use and Land-Cover Change in Montane Mainland Southeast Asia. Environmental Management, 36, 394-403. https://doi.org/10.1007/s00267-003-0288-7

[9] Ian, H. (2010) An Introduction to Geographical Information Systems. Pearson Education India, Chennai.

[10] Krukanont, P. and Prasertsan, S. (2004) Geographical Distribution of Biomass and Potential Sites of Rubber Wood Fired Power Plants in Southern Thailand. Biomass and Bioenergy, 26, 47-59. https://doi.org/10.1016/S0961-9534(03)00060-6

[11] Li, Z. and Fox, J.M. (2012) Mapping Rubber Tree Growth in Mainland Southeast Asia Using Time-Series MODIS $250 \mathrm{~m}$ NDVI and Statistical Data. Applied Geography, 32, 420-432. https://doi.org/10.1016/j.apgeog.2011.06.018

[12] Anderson, A.B. and Ioris, E.M. (1992) The Logic of Extraction: Resource Management and Income Generation by Extractive Producers in the Amazon Estuary. In: Redford, K.H. and Padoch, C., Eds., Conservation of Neotropical Forests. Working from Traditional Resource Use, Columbia University Press, New York, 175-199.

[13] Kelly, P.F. (2009) From Global Production Networks to Global Reproduction Net- 
works: Households, Migration, and Regional Development in Cavite, the Philippines. Regional Studies, 43, 449-461. https://doi.org/10.1080/00343400902777075

[14] Langran, G. and Chrisman, N.R. (1988) A Framework for Temporal Geographic Information. Cartographica: The International Journal for Geographic Information and Geovisualization, 25, 1-14. https://doi.org/10.3138/K877-7273-2238-5Q6V

[15] Leckie, D.G. and Gillis, M.D. (1995) Forest Inventory in Canada with Emphasis on Map Production. The Forestry Chronicle, 71, 74-88. https://doi.org/10.5558/tfc71074-1

[16] Rallos, R.V., Asio, V.B. and Villamayor, F.P. (2017) Soil-Landscape Relationship in the Northern Volcanic Mountain of Leyte, Philippines. Annals of Tropical Research, 39, 87-104. https://doi.org/10.32945/atr3916.2017

[17] Liu, W., Hu, H., Ma, Y. and Li, H. (2006) Environmental and Socioeconomic Impacts of Increasing Rubber Plantations in Menglun Township, Southwest China. Mountain Research and Development, 26, 245-253. https://doi.org/10.1659/0276-4741(2006)26[245:EASIOI]2.0.CO;2

[18] Penot, E., Ruf, F. and Gérard, F. (2001) Rubber Cushions the Smallholder: No Crisis, No Windfall. In: Agriculture in Crisis: People, Commodities and Natural Resources in Indonesia, 1996-2000, Curzon Press, Richmond, 237-266.

[19] Alcala, E.A. (2007) Rubber: Manual for Rubber Smallholders in the Philippines. USM and PRBI, Kabacan.

[20] Orimoloye, J.R., Ugwa, I.K. and Idoko, S.O. (2010) Soil Management Strategies for Rubber Cultivation in an Undulating Topography of Northern Cross River State. Journal of Soil Science and Environmental Management, 1, 34-39.

[21] Oku, E., Iwara, A. and Ekukinam, E. (2012) Effects of Age of Rubber (Hevea brasiliensis Muell Arg.) Plantation on pH, Organic Carbon, Organic Matter, Nitrogen and Micronutrient Status of Ultisols in the Humid Forest Zone of Nigeria. Kasetsart Journal-Natural Science, 46, 684-693.

[22] Oh, H.J. and Lee, S. (2011) Landslide Susceptibility Mapping on Panaon Island, Philippines Using a Geographic Information System. Environmental Earth Sciences, 62, 935-951. https://doi.org/10.1007/s12665-010-0579-2 